\title{
Suplementação Energética para Vacas de Descarte de Diferentes Idades em Terminação em Pastagem Cultivada de Estação Fria sob Pastejo Horário

\author{
João Restle ${ }^{1}$, Cledson Roso², André Nunes de Oliveira ${ }^{3}$, Dari Celestino Alves Filho4, \\ Leonir Luíz Pascoal ${ }^{5}$, Joilmaro Rodrigo Pereira Rosa ${ }^{6}$
}

\begin{abstract}
RESUMO - O experimento foi realizado para avaliar o efeito da suplementação energética sobre o desempenho de vacas de descarte em terminação submetidas ao pastejo horário em pastagem de triticale mais azevém. O suplemento energético usado foi composto por grãos de sorgo triturado nos níveis de $0 ; 0,3 ; 0,6$; e $0,9 \%$ do peso vivo. Foram usadas 40 vacas de descarte da raça Charolês, divididas em classes, em função da idade, e distribuídas ao acaso nos níveis de suplemento. Não houve interação entre idade da vaca e nível de suplementação. O aumento nos níveis de suplementação não influenciou o ganho de peso médio diário (GMD), que foi de 1,$483 ; 1,437$; 1,476; e 1,510 kg para os níveis de 0 a $0,9 \%$, respectivamente. A pastagem proporcionou aporte de nutrientes suficiente para a expressão do potencial máximo de ganho de peso dos animais. O estado corporal final aumentou linearmente com o acréscimo nos níveis de suplementação. O GMD foi maior nas vacas de quatro anos (1,608 kg), decrescendo linearmente com o avanço da idade, chegando a 1,333 kg para as vacas acima de nove anos. O estado corporal apresentou relação quadrática frente à idade das vacas, melhorando até a idade de sete a oito anos e declinando após.
\end{abstract}

Palavras-chave: azevém, Charolês, estado corporal, ganho de peso, triticale

\section{Energy Supplementation for Finishing Cull Cows of Different Ages on Cultived Winter Pasture under Temporary Grazing}

\begin{abstract}
The experiment was conducted to evaluate the effect of energy supplementation on the performance of finishing cull cows under temporary grazing on triticale plus ryegrass. The energy supplement was ground sorghum in the levels of $0, .3, .6$ and .9\% of the live weight. Forty Charolais cull cows were divided in age classes and randomly distributed on the supplementation levels. No interaction was observed between age of the cow and supplementation level. The increase of supplementation level did not affect the average daily weight gain (ADG), which was $1.483,1.437,1.476$ and $1.510 \mathrm{~kg}$ for the levels from 0 to $.9 \%$, respectively. The results showed that the pasture supplied the nutrients for the animals express the maximum potential for weight gain. The final body condition linearly increased as the supplementation level increased. The ADG was higher for the four year old cows (1.608 kg), linearly declining with the increase of age, reaching $1.333 \mathrm{~kg}$ for the cows above nine years old. Body condition showed a quadratic relation with age, improving up to seven/eight years and declining afterward.
\end{abstract}

Key Words: body condition, Charolais, ryegrass, triticale, weight gain

\section{Introdução}

A taxa de abate de fêmeas no Brasil vem aumentado nos últimos dez anos, atingindo o seu maior índice (49,5\%) em 1996 (ANUALPEC, 1997). No Rio Grande do Sul, este índice foi ainda maior, chegando aos $56,7 \%$. Estes dados mostram a importância da vaca de descarte na produção de carne nacional.

A terminação de vacas no sul do país tem sido realizado comumente em condições de pastagem nativa, sendo que o abate de fêmeas se concentra principalmente no período do outono. Nessa época do ano, o preço pago pelos frigoríficos pelo bovino gordo atinge seu valor mais baixo. Além disso, a diferença de remuneração por $\mathrm{kg}$ de peso vivo ou de carcaça entre novilho e vaca é maior nesse período. A terminação de vacas no sul do país, visando a sua comercialização no período em que o preço pago pelos frigoríficos atinge o seu valor mais alto, é uma alternativa para aumentar a

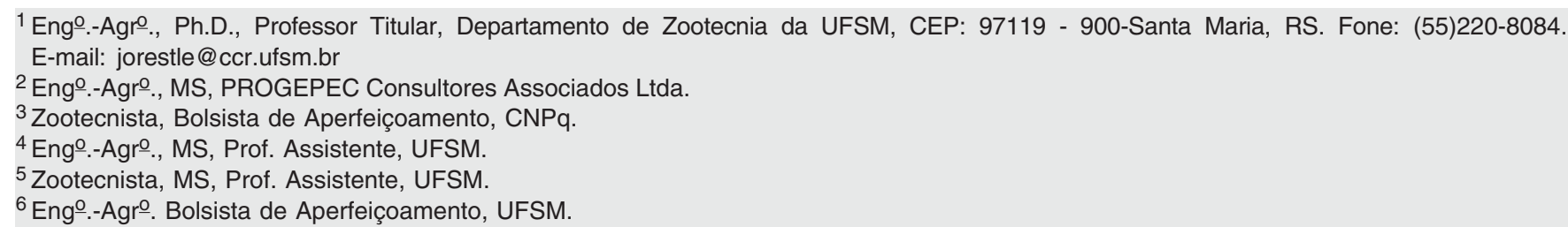


rentabilidade do produtor. Este período compreende os meses de agosto a outubro, portanto, é necessário investir na alimentação, já que o campo nativo não oferece condições qualitativas para que a vaca atinja condições de abate.

A terminação de vacas em pastagens cultivadas de inverno é um processo de baixa eficiência biológica. RESTLE et al. (1998) verificaram que as vacas Charolês na fase de terminação em pastagem de aveia mais azevém consumiram $13,8 \mathrm{~kg}$ de $\mathrm{MS} / \mathrm{kg}$ de ganho de peso, ao passo que novilhos de sobreano, $8,3 \mathrm{~kg}$ de $\mathrm{MS} / \mathrm{kg}$ de ganho de peso. No entanto, segundo RESTLE e BRONDANI (1998), apesar da baixa eficiência alimentar observada, a terminação de vacas para comercialização na entresafra tem mostrado boa rentabilidade no sul do país, principalmente pelo aumento do preço por kg de peso pago na primavera em relação ao verificado no outono.

A suplementação de bovinos com alimentos energéticos em pastagem cultivada de inverno, visando à terminação, é uma técnica que vem avançando rapidamente no sul do país (PASCOAL e RESTLE, 1998). As pastagens cultivadas de inverno, como triticale, aveia e azevém, apresentam alta digestibilidade e elevados níveis de proteína bruta (PB), no entanto, a sua concentração de matéria seca (MS) na fase de crescimento é baixa (LUPATINI et al., 1998; RESTLE et al., 1998). Segundo RESTLE et al. (1998), a DIVMO da massa de forragem da mistura de aveia mais azevém pode ultrapassar os $75 \%$ no início do período de pastejo, quando as espécies estão em pleno crescimento. Já a concentração de MS nessa fase não ultrapassa os $15 \%$ (ROSO, 1998), o que pode limitar o consumo diário de MS pela limitação física do rúmen. Por outro lado, o teor de PB é elevado, chegando a 27\% (ROSO, 1998), sendo muito superior às exigências mesmo para animais em crescimento (NATIONAL RESEARCH COUNCIL - NRC, 1996).

Conforme citado por GOETSCH et al. (1991), a suplementação de animais mantidos em pastagem com alimentos rapidamente fermentáveis no rúmen pode melhorar o desempenho animal por meio de melhor aproveitamento do nitrogênio da forragem, incremento da produção de proteína microbiana e aumento do propionato e o total de ácidos graxos voláteis. Também, segundo PASCOAL e RESTLE (1998), os concentrados energéticos, por apresentarem alto teor de MS, alta velocidade de passagem pelo rúmen, alta digestibilidade e boa palatabilidade, podem favorecer o desempenho animal. O aumento no desempenho é esperado, pois ocorre consumo maior de energia, devido ao fato de o concentrado apresentar maior digestibilidade e o consumo total de MS aumentar. A suplementação com um concentrado energético para animais mantidos em pastagem de inverno permite melhor balanceamento de nutrientes na dieta do animal, podendo resultar em efeito aditivo.

O pastejo horário em pastagem cultivada de inverno visa melhorar a eficiência da utilização das mesmas, pois reduz as perdas causadas por pisoteio e dejeções. Esta técnica tem sido usada com bons resultados na redução da idade de abate de novilhos (MÜLLER et al., 1980).

Maior aporte de energia, por meio da suplementação de alimentos concentrados, pode ter importância principalmente em animais cujos ganhos de peso requerem mais energia, como é o caso de vacas de descarte em terminação, pelo fato destes animais já terem completado o seu crescimento. Nesse sentido, o presente experimento teve como objetivo avaliar o desempenho de fêmeas de descarte de diferentes idades submetidas a diferentes níveis de suplementação energética associados à pastagem cultivada de inverno.

\section{Materiais e Métodos}

O experimento foi conduzido no Departamento de Zootecnia da Universidade Federal de Santa Maria, situada na Depressão Central do Rio Grande do Sul, numa altitude de $95 \mathrm{~m}$, latitude 2943' sul e longitude $53^{\circ} 42^{\prime}$ ' oeste, no período 18/06 a 19/08/97.

Foram avaliados quatro níveis de suplementação para vacas de descarte na fase de terminação submetidas a pastejo horário em pastagem de triticale (Xtriticosecale) mais azevém (Lolium multiflorum). Foram testados os seguintes tratamentos:

NS 0 - Pastejo horário sem suplemento;

NS 03 - Pastejo horário + suplemento equivalente a $0,3 \%$ do peso vivo (PV);

NS 06 - Pastejo horário + suplemento equivalente a $0,6 \%$ do PV; e

NS 09 - Pastejo horário + suplemento equivalente a $0,9 \%$ do PV.

Foram utilizadas 40 vacas de descarte da raça Charolês, oriundas do mesmo rebanho do Departamento de Zootecnia da Universidade Federal de Santa Maria. A idade das vacas variou de quatro a doze anos, sendo as mesmas agrupadas em quatro classes segundo a idade: IV1, vacas com quatro anos; IV2, vacas com cinco e seis anos; IV3, vacas com 
1218 Rev. bras. zootec.

sete e oito anos; e IV4, vacas com mais de nove anos. As vacas de cada classe de idade foram distribuídas ao acaso nos quatro tratamentos.

A pastagem foi estabelecida em 26 e 27 de abril de 1997. Utilizaram-se $140 \mathrm{~kg} / \mathrm{ha}$ de semente de triticale com plantio direto em linha. A quantidade de sementes de azevém foi de $35 \mathrm{~kg} / \mathrm{ha}$, sendo a metade distribuída em linha junto com o triticale e a outra metade, a lanço sem incorporação. No plantio, foram utilizados $350 \mathrm{~kg} / \mathrm{ha}$ de adubo da fórmula 10-18-20. Foi realizada adubação nitrogenada em cobertura na forma de uréia $(200 \mathrm{~kg} / \mathrm{ha})$ parceladas e aplicadas nas datas de 10/07 e 02/08/97.

Para determinar a massa de forragem, realizaram-se avaliações na pastagem, no início do período experimental, e a cada 21 dias, através do corte de 20 amostras de $0,25 \mathrm{~m}^{2}$, tomadas ao acaso na área. Por ocasião das avaliações, retirava-se uma amostra composta para posterior determinação da MS, PB e digestibilidade in vitro da matéria orgânica (DIVMO) e fibra detergente neutro (FDN).

Os animais pastejaram sempre na mesma área, sendo empregado o pastejo horário, duas horas pela manhã ( 8 às $10 \mathrm{~h}$ ) e duas horas pela tarde (16 às $18 \mathrm{~h}$ ). A lotação foi variável, utilizando a técnica "Put and take" (MOTT e LUCAS, 1952), procurando-se manter uma massa de forragem disponível próxima a $1300 \mathrm{~kg} / \mathrm{ha}$ de MS.

O suplemento utilizado foi composto de grãos de sorgo triturado, fornecido em cochos de madeira, com acesso de 1,05 m por animal. O suplemento foi fracionado em duas partes, fornecidas duas vezes ao dia logo após o período de pastejo. No período de descanso, os animais permaneciam em uma área de 1,5 ha de campo nativo, onde tinham à disposição água e cloreto de sódio à vontade.

O período de adaptação dos animais à pastagem e ao suplemento, aumentado gradativamente, teve duração de sete dias (11/06 a 17/06).

Sabendo-se de antemão da queda do crescimento da pastagem durante o período de julho, reduziu-se a carga animal, que era alta no primeiro período, fazendo com que a massa de forragem voltasse a subir no terceiro período. Com este manejo, visou-se evitar o alongamento dos entrenós e elevação do ponto de crescimento, que, por intermédio do pastejo, é facilmente eliminado pelos animais.

O período experimental teve início em 18/06 e foi subdividido em dois períodos de 21 dias (18/06 a 08/07 e 09/07 a 30/07) e um período de 20 dias (31/07 a 19/08). As pesagens foram realizadas no início de cada período, antes da entrada dos animais na pastagem, e no final do experimento. Por ocasião da última pesagem, realizou-se a avaliação do estado corporal dos animais, segundo RESTLE (1972), atribuindo os seguintes escores: EC1: muito magro, EC2: magro, EC3: médio, EC4: gordo e EC5: muito gordo.

O delineamento experimental foi inteiramente casualizado. Efetuou-se a análise da variância por meio do método dos quadrados mínimos (SAS, 1990), cujo o modelo estatístico incluiu os efeitos fixos de nível de suplementação, idade da vaca, período e as interações entre esses efeitos. Como não houve interação significativa entre os efeitos principais para nenhuma das variáveis estudadas, os dados foram analisados por análise de regressão, segundo o nível de suplementação e a idade da vaca.

\section{Resultados e Discussão}

Na Tabela 1, encontram-se os dados referentes à pastagem cultivada. A massa de forragem disponível foi de $1276 \mathrm{~kg} / \mathrm{ha}$ de MS na média das três avaliações, ficando próxima ao estipulado inicialmente. $\mathrm{Na}$ segunda avaliação realizada entre 09/07 e 30/07, houve queda na massa de forragem disponível (1178 $\mathrm{kg} / \mathrm{ha}$ ), que foi consequência da redução na taxa de crescimento das espécies que normalmente ocorre durante o mês de julho, em função da baixa luminosidade e queda da temperatura (ROSO, 1998).

A carga animal média foi de $1362 \mathrm{~kg}$ de peso vivo/ha. No primeiro período de pastejo, foi utilizada maior carga animal, visando reduzir a massa de forragem, que, segundo avaliação, foi estimada em $1700 \mathrm{~kg}$ de matéria seca/ha.

O teor de MS da massa de forragem disponível foi baixo no primeiro período, concordando com os resultados obtidos por ROSO (1998), o qual verificou que o teor de MS no início do pastejo em pastagem cultivada de inverno não ultrapassou os $15 \%$. Já nos demais períodos houve aumento no teor de MS, passando dos $13,8 \%$ iniciais para $20,3 \%$ no período de 31/07 a 19/08. Este acréscimo se deve ao fato de que, com o pastejo, há diminuição na relação folha/caule, sendo o caule a porção onde há maior concentração de carboidratos estruturais.

$\mathrm{O}$ teor de PB foi baixo no primeiro período, diferindo dos resultados obtidos por LUPATINI et al. (1998), RESTLE et al. (1998) e ROSO (1998), em que os maiores valores de PB foram obtidos no primeiro período de pastejo. Nos demais períodos, o teor de PB foi mais elevado. O aumento do teor de PB 
a partir do segundo período deve-se em parte à adubação nitrogenada que foi realizada entre o primeiro e o segundo períodos e entre o segundo e terceiro períodos. O teor de $\mathrm{PB}$ médio do período experimental foi de $20,0 \%$, ficando muito acima das exigências em PB para a categoria vacas em terminação (NRC, 1996).

A DIVMO foi semelhante nos dois primeiros períodos, ficando na faixa dos $63 \%$, aumentando para $66,1 \%$ no período de $31 / 07$ a 19/08, devido basicamente ao aumento da contribuição do azevém, que apresenta maior DIVMO (ROSO, 1998). Os maiores valores de FDN foram obtidos nos períodos de menor DIVMO e os menores valores, nos períodos de maior DIVMO; isto está relacionado, principalmente, ao elevado crescimento do azevém no período de 31/07 a 19/08, no qual houve menor acúmulo de material estrutural.

O consumo médio diário de suplemento encontra-se na Tabela 2. Observa-se que, com o passar dos períodos, houve aumento no consumo de sorgo triturado, o que ocorreu em função do aumento do PV dos animais e do consumo estar associado ao PV.

$\mathrm{Na}$ Tabela 3, encontram-se os valores médios ajustados referentes ao desempenho dos animais. Não houve interação significativa entre idade da vaca e nível de suplemento para as variáveis estudadas. Observa-se que os pesos iniciais e finais foram semelhantes e que o nível de suplemento não influenciou o GMD durante o período de terminação das vacas, portanto, o aumento do nível de suplemento não proporcionou efeito aditivo ao consumo de nutrientes na dieta dos animais. Resultados semelhantes em

Tabela 1 - Massa de forragem (kg MS/ha), carga animal ( $\mathrm{kg}$ de PV/ha), matéria seca (\%), proteína bruta (\%), fibra detergente neutro (FDN) (\%) e digestibilidade in vitro da matéria orgânica (DIVMO) (\%), de acordo com o período

Table 1 - Forage mass (kg DM/ha), stocking rate (kg LW/ha), dry matter (\%), crude protein (\%), neutral detergent fiber (NDF) (\%) and in vitro organic matter digestibility (IVOMD) (\%), according to the period

\begin{tabular}{lcccc}
\hline $\begin{array}{l}\text { Variáveis } \\
\text { Variables }\end{array}$ & \multicolumn{4}{c}{$\begin{array}{c}\text { Período } \\
\text { Period }\end{array}$} \\
\cline { 2 - 5 } & $\begin{array}{l}\text { 18/06 a 08/07 } \\
\text { 06/18 to 07/08 }\end{array}$ & $\begin{array}{c}09 / 07 \text { a 30/07 } \\
\text { 07/09 to 07/30 }\end{array}$ & $\begin{array}{c}31 / 07 \text { a 19/08 } \\
\text { 07/31 to 08/19 }\end{array}$ & $\begin{array}{c}\text { Média } \\
\text { Mean }\end{array}$ \\
\hline $\begin{array}{l}\text { Massa de forragem } \\
\text { Forage mass } \\
\text { Carga animal } \\
\begin{array}{l}\text { Stocking rate } \\
\text { Matéria seca }\end{array}\end{array}$ & 1350 & 1178 & 1300 & 1276 \\
$\begin{array}{l}\text { Dry matter } \\
\text { Proteína bruta } \\
\text { Crude protein } \\
\text { DIVMO }\end{array}$ & 1736 & 1131 & 1219 & 1362 \\
$\begin{array}{l}\text { IVOMD } \\
\text { FDN }\end{array}$ & 13,8 & 18,3 & 20,3 & 17,5 \\
NDF & 14,8 & 22,9 & 22,2 & 20,0 \\
\hline
\end{tabular}

Tabela 2 - Consumo médio diário (kg/animal) de sorgo triturado*, expresso em matéria seca total por período e nível de suplementação

Table 2 - Average daily intake (kg/animal) of ground sorghum ${ }^{*}$ express in total dry matter, according to the period and supplementation level

\begin{tabular}{lcccc}
\hline $\begin{array}{l}\text { Nível de } \\
\text { suplementação (NS) }\end{array}$ & \multicolumn{3}{c}{$\begin{array}{c}\text { Período } \\
\text { Period }\end{array}$} \\
\cline { 2 - 4 } \begin{tabular}{l} 
Supplementation level (SL) \\
\cline { 2 - 4 }
\end{tabular} & $\begin{array}{c}\text { 18/06 a 08/07 } \\
\text { 06/18 to 07/08 }\end{array}$ & $\begin{array}{c}\text { 07/09 to 07/30 } \\
\text { 07/31 to 08/19 }\end{array}$ & $\begin{array}{c}\text { Média } \\
\text { Mean }\end{array}$ \\
\hline NS 03 & 1,001 & 1,104 & 1,186 & 1,097 \\
SL 03 & 1,998 & 2,224 & 2,374 & 2,199 \\
NS 06 & 2,996 & 3,316 & 3,582 & 3,298 \\
SL 06 & & & &
\end{tabular}

* Teor de matéria seca do sorgo foi de $88 \%$ e DIVMO, de $82,26 \%$.

* Sorghum dry matter content was $88 \%$ and IVOMD was $82.26 \%$. 
Tabela 3 - Valores médios ajustados e erros-padrão para peso inicial, peso final, ganho de peso médio diário (GMD) e estado corporal final (EC), para vacas de descarte, de acordo com o nível de suplementação

Table 3 - Average adjusted values and standard errors for initial weight, final weight, average daily gain (ADG) and final body condition $(B C)$ for finishing cull cows according to the supplementation level

\begin{tabular}{lcccc}
\hline $\begin{array}{l}\text { Nível suplementação (NS) } \\
\text { Supplementation level (SL) }\end{array}$ & $\begin{array}{c}\text { Peso inicial (kg) } \\
\text { Initialweight }\end{array}$ & $\begin{array}{c}\text { Peso final }{ }^{1}(\mathrm{~kg}) \\
\text { Final weight }^{1}\end{array}$ & $\begin{array}{c}\mathrm{GMD}^{1}(\mathrm{~kg}) \\
A D G^{1}\end{array}$ & $\begin{array}{c}\mathrm{EC}^{2} \\
B^{2}\end{array}$ \\
\hline NS 0 & $339,0 \pm 10,5$ & $431,0 \pm 13,3$ & $1,483 \pm 0,105$ & $3,48 \pm 0,12$ \\
SL 0 & $341,9 \pm 10,9$ & $431,0 \pm 13,9$ & $1,437 \pm 0,200$ & $3,56 \pm 0,13$ \\
NS 03 & $334,0 \pm 10,5$ & $425,5 \pm 13,2$ & $1,476 \pm 0,105$ & $3,87 \pm 0,12$ \\
SL 03 & & & \\
NS 06 & $338,2 \pm 10,7$ & $431,8 \pm 13,5$ & $1,510 \pm 0,107$ & $3,97 \pm 0,12$ \\
SL 06 & & & &
\end{tabular}

$1 \mathrm{P}>0,05$.

$2 Y=3,365+0,633 N S(P<0,0052)$.

$1 P>05$.

$2 Y=3.365+.633 S L(P<.0052)$.

ganho de peso também foram encontrados por RESTLE et al. (1999), suplementando novilhos em pastagem cultivada de inverno com 0,5 e $1 \%$ do PV com grão de milho moído, no período de 05/09 a 10/ 11. Já RESTLE et al. (1996) obtiveram incremento no GMD em vacas de descarte em pastejo contínuo em pastagem de aveia + azevém, com o aumento do nível de suplementação de 0 para $0,4 \%$ do peso vivo, ocorrendo efeito aditivo do suplemento. No entanto, a suplementação naquele trabalho foi realizada no período de 09/09 a 25/11/96, ou seja, quando a pastagem se apresentava em fase mais avançada de desenvolvimento, sendo a DIVMO média de $56,88 \%$ inferior à DIVMO do presente experimento (64\%). A semelhança no GMD, com o aumento nos níveis de suplemento obtido nesse experimento, pode ser explicada, principalmente, pelo efeito substitutivo no consumo, no qual houve substituição do consumo da pastagem pelo suplemento, sem alterar o GMD. O fato de o grão de sorgo não ter influenciado o GMD deve-se à elevada qualidade da pastagem. A DIVMO da pastagem atingiu $66,1 \%$ no terceiro período e, como os animais selecionam o material a ser consumido, a qualidade da forragem consumida deve ter sido superior à das amostras analisadas, já que estas foram cortadas rente ao solo.

Segundo GOETSCH et al. (1991), a adição de grãos na dieta pode causar redução na digestibilidade das fibras da forragem, o que afetaria o desempenho dos animais. No presente experimento, o GMD não foi alterado pela inclusão de sorgo na dieta, o que é indicativo de que, se ocorreram alterações no rúmen, estas não afetaram o desempenho dos animais, mesmo no nível mais alto de suplementação, que representou $32 \%$ do consumo diário estimado de MS, caso seja considerado o consumo de $2,68 \mathrm{~kg} / 100 \mathrm{~kg}$ de PV, encontrado por SILVA e RESTLE (1990) para vacas Charolês. Deve ser ressaltado, no entanto, que o concentrado foi fracionado em duas partes e fornecido logo após o período de pastejo, por conseguinte, este manejo deve ter minimizado as alterações ruminais que podem ocorrer com a suplementação de grãos para animais cuja dieta básica é forragem.

O GMD no período experimental foi de $1,476 \mathrm{~kg}$, sendo superior aos encontrados por RESTLE e GRASSI (1993) e RESTLE et al. (1998) em pastejo contínuo sem suplementação, com vacas de descarte e pastagem semelhante à usada neste experimento, e por RESTLE et al. (1996), com suplementação em pastejo contínuo em aveia + azevém.

$\mathrm{O}$ efeito substitutivo do consumo de forragem pelo suplemento, mesmo sem adição no GMD, é desejado em situações em que ocorrem oscilações no crescimento das forrageiras e se deseja manter carga animal fixa na área de pastagem. Nesse caso, podem-se variar os níveis de suplemento, fazendo com que exista equilíbrio entre a produção de MS das forrageiras e o consumo de MS pelos animais. Este equilíbrio proporciona sempre massa de forragem adequada à máxima produção de MS pela pastagem e expressão de todo o potencial genético para consumo de MS e, conseqüentemente, para ganho de peso pelos animais. Outro aspecto a ser considerado é que o efeito substitutivo, embora não eleve o GMD, resulta em aumento da carga animal/ha, pelo menor consumo de forragem, com isto o ganho de $\mathrm{PV} / \mathrm{ha}$ também será aumentado (HORN et al., 1995). No 
presente experimento, o ganho de peso/ha para os quatro níveis de suplementação não teve condições de ser medido separadamente, já que os animais permaneciam na mesma área.

O estado corporal final das vacas (Tabela 3) elevouse de forma linear com o aumento dos níveis de suplemento. Isto mostra que, apesar de não ter ocorrido diferença no GMD entre os níveis de suplemento, houve maior aporte energético aos animais com o aumento nos níveis de suplemento. Isto fez com que a composição do ganho de peso fosse diferente, ocorrendo maior deposição de gordura nas vacas que receberam maior percentual de suplemento, refletindo-se na melhoria do estado corporal. Segundo GOETSCH et al. (1991), que revisaram vários trabalhos sobre a adição de grãos em dietas à base de forragem, a suplementação com grãos rapidamente fermentáveis pode aumentar o aporte de energia pela elevação na produção de propionato e o total de ácidos graxos voláteis, a digestão intestinal do amido que escapa à degradação ruminal e o aumento do fluxo da matéria orgânica dos microrganismos que atingem o intestino.

Melhorar o estado corporal dos animais, além do ganho de peso, é um aspecto importante, quando se deseja obter grau de acabamento mais precoce, possibilitando a comercialização antecipada dos animais, pois os frigoríficos exigem animais com ade- quada cobertura de gordura.

$\mathrm{Na}$ Tabela 4, encontram-se os valores relativos às variáveis observadas nos animais em função da idade. Observa-se que o peso inicial, o peso final e o estado corporal apresentaram comportamento quadrático, em função da idade da vaca. Estas variáveis aumentaram de forma significativa até as idades de 7 e 8 anos e diminuíram a partir destas. Já o GMD foi superior nas vacas com menor idade, sendo que esta variável sofreu comportamento linear negativo em função da idade. Isso mostra que animais mais jovens apresentam maior GMD, com composição do ganho de peso diferente à dos animais de idade mais avançada. Neste caso, houve maior ganho muscular e menor ganho em tecido adiposo, conferindo menor estado corporal aos animais mais jovens. O ganho de peso das fêmeas de quatro anos foi similar ao relatado por RESTLE et al. (1998) para novilhos de dois anos, oriundos do mesmo rebanho e terminados exclusivamente em pastagem cultivada de inverno.

O bom desempenho dos animais mais jovens mostra que esta categoria é importante no sistema de terminação de bovinos. A proporção desta categoria na produção de carne deverá aumentar, à medida que a taxa de reprodução se elevar e a idade ao primeiro acasalamento reduzir, permitindo maior descarte de fêmeas do rebanho.

Tabela 4 - Valores médios e erros-padrão para peso inicial (PI), peso final (PF), ganho de peso médio diário (GMD) e estado corporal final (EC), conforme a idade da vaca

Table 4 - Average values and standard errors for initial weight (IW), final weight (FW), average daily gain (ADG) and final body condition (BC), according to the cow age

\begin{tabular}{lcccc}
\hline $\begin{array}{l}\text { Idade da vaca }(\mathrm{IV}) \\
\text { Cow age }(C A)\end{array}$ & $\mathrm{PI}^{1}(\mathrm{~kg})$ & $\mathrm{PF}^{2}(\mathrm{~kg})$ & $\mathrm{GMD}^{3}(\mathrm{~kg})$ & $\mathrm{EC}^{4}$ \\
IV1 & $W^{1}$ & $F W^{2}$ & $A D G^{3}$ & $B C^{4}$ \\
CA1 & $304,9 \pm 08,3$ & $404,6 \pm 10,5$ & $1,608 \pm 0,083$ & $3,33 \pm 0,10$ \\
IV2 & $337,1 \pm 12,5$ & $432,2 \pm 15,8$ & $1,534 \pm 0,125$ & $3,76 \pm 0,14$ \\
CA2 & $362,9 \pm 09,9$ & $452,1 \pm 12,6$ & $1,439 \pm 0,099$ & $3,93 \pm 0,11$ \\
IV3 & & & \\
CA3 & $348,1 \pm 13,5$ & $430,7 \pm 17,1$ & $1,333 \pm 0,135$ & $3,85 \pm 0,16$ \\
IV4 & & & \\
CA4 & & &
\end{tabular}

$1 \hat{\mathrm{Y}}=241,97+74,30 \mathrm{IV}-11,81 \mathrm{IV}(C A)^{2}(\mathrm{P}<0,0001)$.

$2 \hat{\mathrm{Y}}=344,93+71,54 \mathrm{IV}-12,40 \mathrm{IV}(C A)^{2}(\mathrm{P}<0,0167)$.

$3 \hat{\mathrm{Y}}=1,700-0,089 \mathrm{IV}(C A)^{2}(\mathrm{P}<0,0486)$.

$4 \hat{\mathrm{Y}}=2,546+0,916$ IV $-0,148 \mathrm{IV}(C A)^{2}(\mathrm{P}<0,0006)$. 


\section{Conclusões}

A suplementação energética com grãos de sorgo triturado não proporciona incremento no ganho médio diário de vacas em terminação em pastagem cultivada de inverno submetidas ao pastejo horário, quando o tempo de pastejo for adequado e a massa de forragem disponível para pastejo apresentar boa disponibilidade e qualidade.

O aumento nos níveis de suplemento proporciona melhoria no estado corporal final aos animais, conferindo grau de acabamento mais rápido, com possibilidade de comercialização antecipada.

A suplementação energética em pastagem cultivada de inverno provoca a substituição do consumo de forragem da pastagem pelo suplemento, proporcionando aumento na carga animal suportada pela pastagem e, conseqüentemente, na terminação de maior número de animais em uma mesma área.

\section{Referências Bibliográficas}

ANUALPEC, 1997. Anuário estatístico da produção animal. FNP. São Paulo: Gráfica Editora Camargo Soares Ltda. 329p.

GOETSCH, A.L., MURPHY, G.E., GRANT, E.W. et al. 1991. Effects of animal and supplement characteristics on average daily gain of grazing beef cattle. J. Anim. Sci., 69:433-442.

HORN, G.W., CRAVEY, M.D., McCOLLUM, F.T. et al. 1995. Influence of high-starch vs high-fiber energy supplements on performance of stocker cattle grazing wheat pasture and subsequent feedlot performance. J. Anim. Sci. 73:45-54.

LUPATINI, G.C., RESTLE, J., CERETTA, M. et al. 1998. Avaliação da mistura de aveia preta (Avena strigosa) e azevém (Lolium multiflorum) sob pastejo submetida a níveis de nitrogênio. I - Produção e qualidade de forragem. Pesq. Agropec. Bras., 33(11):1939-1943.

MOTT, G.O., LUCAS, H.L. 1952. The design conduct and interpretation of grazing trials on cultivated and improved pastures. In: INTERNATIONAL GRASSLAND CONGRESS, 6, 1952. Proceedings... Pensylvania, State College Press., p.1380-1395.

MÜLLER, L., RESTLE, J., BANDEIRA, A. et al. Utilização da pastagem cultivada de inverno em regime permanente ou temporário e seu efeito no desempenho de novilhos. In: REUNIÃO ANUAL DA SOCIEDADE BRASILEIRA DE ZOOTECNIA, 17, 1980, Fortaleza. Anais... Fortaleza: SBZ, 1980, p. 515
NATIONAL RESEARCH COUNCIL - NRC. 1996. Nutrient requirement of beef cattle. 6.ed. Washington: National Academy Press. 90p.

PASCOAL, L.L., RESTLE, J. 1998. Terminação de bovinos de corte com suplemento energético em pastagem cultivada de inverno. In: RESTLE, J., BRONDANI, I.L., PASCOAL, L.L. et al. (Eds.) Produção intensiva com qualidade em bovinos de corte. Santa Maria. p.18-29.

RESTLE, J., BRONDANI, I.L. 1998. Eficiência na terminação de vacas e novilhos In: RESTLE, J., BRONDANI, I.L., PASCOAL, L.L. et al. Produção intensiva com qualidade em bovinos de corte. Santa Maria: UFSM. p.49-57.

RESTLE, J. 1972. Comportamento reprodutivo do rebanho de gado de corte da Fazenda Experimental Agronômica da UFRGS. Apresentado como seminário na disciplina de Técnicas de pesquisa do CPG da Faculdade de Agronomia da UFRGS.

RESTLE, J., GRASSI, C. 1993. Castração de vacas de descarte e seu efeito no ganho de peso da vaca e do bezerro. Pesq. Agropec. Bras., 28(12):1437-1441.

RESTLE, J., PASCOAL, L.L., OLIVEIRA, A.N. Desempenho de vacas de descarte suplementadas em pastagem cultivada com níveis de suplementação. In: DIA DE CAMPO DO SETOR DE GADO DE CORTE, 1996, Santa Maria. p.9-10, 1996.

RESTLE, J., LUPATINI, G.C., ROSO, C. et al. 1998. Eficiência e desempenho de diferentes categorias de bovinos de corte em pastagem cultivada. R. Bras. Zootec., 27(2):397-404.

RESTLE, J., SOARES, A.B., FERREIRA, M.V.B. et al. 1999. Suplementação associada com lasalocida para novilhos em terminação em pastagem cultivada de inverno. R. Ciência Rural, 29(3):555:559.

ROSO, C. Produção animal em misturas de gramíneas anuais de estação fria. Santa Maria - RS: UFSM, 1998. 104p. Dissertação (Mestrado em Zootecnia) - Universidade Federal de Santa Maria, 1998.

SAS. 1990. Language reference. Version 6, Cary, NC: SAS Institute Inc., $1042 \mathrm{p}$.

SILVA, L.L., RESTLE, J. Desempenho de vacas de corte de dois grupos genéticos terminadas em regime de confinamento. In REUNIÃO ANUAL DA SOCIEDADE BRASILEIRA DE ZOOTECNIA, 27, 1990, Campinas. Anais... Viçosa: SBZ, 1990, p.474.

Recebido em: 03/08/1999

Aceito em: 23/02/2000 